\title{
Experimental investigation of coarse particles-water mixture flow in horizontal and inclined pipes
}

\author{
Pavel Vlasák ${ }^{*}$ Zdeněk Chára, Jan Krupička, Jiří Konfršt \\ Institute of Hydrodynamics of the Academy of Sciences of the Czech Republic, v. v. i., Pod Pat'ankou 30/5, 16612 Prague 6, Czech \\ Republic. \\ ${ }^{*}$ Corresponding author. E-mail: vlasak@ih.cas.cz
}

\begin{abstract}
The effect of solid concentration and mixture velocity on the flow behaviour, pressure drops, and concentration distribution of coarse particle-water mixtures in horizontal, vertical, and inclined smooth stainless steel pipes of inner diameter $\mathrm{D}=100 \mathrm{~mm}$ was experimentally investigated. Graded basalt pebbles were used as solid particles. The study revealed that the coarse-grained particle-water mixtures in the horizontal and inclined pipes were significantly stratified. The solid particles moved principally in a layer close to the pipe invert; however for higher and moderate flow velocities, particle saltation became the dominant mode of particle conveyance. Frictional pressure drops in the horizontal pipe were found to be markedly higher than in the vertical pipe, while the frictional pressure drops in the ascending pipe increased with inclination angle up to about $30^{\circ}$.
\end{abstract}

Keywords: Hydraulic pipelining; Coarse-grained slurry; Pressure drops; Pipe inclination; Concentration distribution.

\section{INTRODUCTION}

Pipeline transport of coarse material is not very frequently used due to the problems of high operational velocities and energy requirements, strong wear of the pipe, and material degradation. However, pipeline transport of coarse-grained mixtures is of potential importance, for example, the mining industry. Hydraulic pipelining is the preferred way of transporting poly-metallic nodules from the ocean bottom to the surface (Vlasak and Chara, 2007; Vlasak et al., 2011b).

The flow of heterogeneous slurries in a horizontal pipe may be defined by an asymmetrical velocity and concentration distribution, where a Coulomb-type friction contributes significantly to the friction losses. A flow pattern with a bed layer and a skewed concentration distribution generally exist for these slurries (Wilson et al., 1979). Settling slurry flow models are based on a semi-empirical rather than a theoretical approach. When a fully stratified mixture flows in a horizontal pipe, a bed load layer originates, the flow area changes from circular to a segment of a circle, and the average liquid velocity increases. The liquid velocity profile becomes asymmetrical due to deformation of the flow area and substantially higher bed roughness (Vlasak et al., 2012, 2014).

Progress in the theoretical description of heterogeneous slurry flow is limited due to the lack of experimental data of the flow behaviour and inner structure of slurry flow, especially for vertical and inclined pipes. A slurry flow mechanism can be theoretically described by the so-called microscopic model (Shook and Roco, 1991). Unfortunately, the experimental technique is not able to provide enough information on the slurry flow mechanism at a microscopic level, and the model remains only theoretical. A compromise between the microscopic and empirical approaches is macroscopic modelling.

The first mechanistic approach for coarse-grained particle slurry flow was probably that of Newitt et al. (1955), who distinguished between velocity-dependent fluid friction and velocity-independent particle-wall friction of the Coulomb type, and defined coarse particle conveyance as flow with a sliding bed and particle saltation. Wilson et al. (2006) interpreted experimental results with highly concentrated glass sphere-water mixtures in smooth pipes and proposed a two-layer model for settling slurries. Based on experimental data from the large diameter $(D=250 \mathrm{~mm})$ pipelines of the Saskatchewan Research Council the two-layer model was extended for finer particles (Shook et al. 1986).

In contrast to literature on heterogeneous slurry flow in horizontal pipes, that on solid-liquid flow through vertical and inclined pipes is rather limited. Most papers are devoted to the vertical transport of sand slurries (Chung et al., 1998; Durand, 1953; Newitt et al., 1961; Shook and Bartosik, 1994; Wilson et al., 1979), mostly in rather narrow pipes.

The main goal of the presented research was an experimental investigation of flow behaviour, pressure drops, and concentration distribution of coarse-grained particle-water mixtures in horizontal, vertical, and inclined pipe sections.

\section{EXPERIMENTAL FACILITY}

The experimental pipe loop in the Institute of Hydrodynamics AS CR, v. v. i., in Prague, which consists of smooth stainless steel pipes of inner diameter $D=100 \mathrm{~mm}$, is suitable for studying the effect of mixture velocity and concentration on flow behaviour, concentration distribution, and pressure drops in horizontal, inclined, and vertical pipe sections (see Fig. 1).

Slurry was prepared in a mixing tank and pumped into the test loop by a GIW LCC-M 80-300 centrifugal slurry pump with variable speed drive. The pressure drops were measured by Rosemount 1151DP DP transmitters in the horizontal and inclined measuring sections, which are fully inclinable from horizontal to vertical. The mean velocities were measured by a Krohne OPTIFLUX 5000 magnetic flow meter, mounted in the short vertical section at the end of the circuit. Mean mixture velocities $V_{s}$ ranged from about $1.5 \mathrm{~m} . \mathrm{s}^{-1}$ close to the deposition limit velocity $\left(V_{c r} \approx 1 \mathrm{~m} \cdot \mathrm{s}^{-1}\right)$ to maximum velocity values about $5.5 \mathrm{~m} . \mathrm{s}^{-1}$.

Transparent viewing pipe sections for visual observation were situated just behind the measuring sections in both the horizontal and the inclinable sections. The vertical U-tube enables evaluation of the transport concentration of the solid phase, $c_{v}$. The flow divider allows collection and weighing of 
slurry samples in the sampling tank of the calibrated volume and measuring of the transport (delivered) concentration of solids and slurry flow rate (Krupicka and Matousek, 2011).

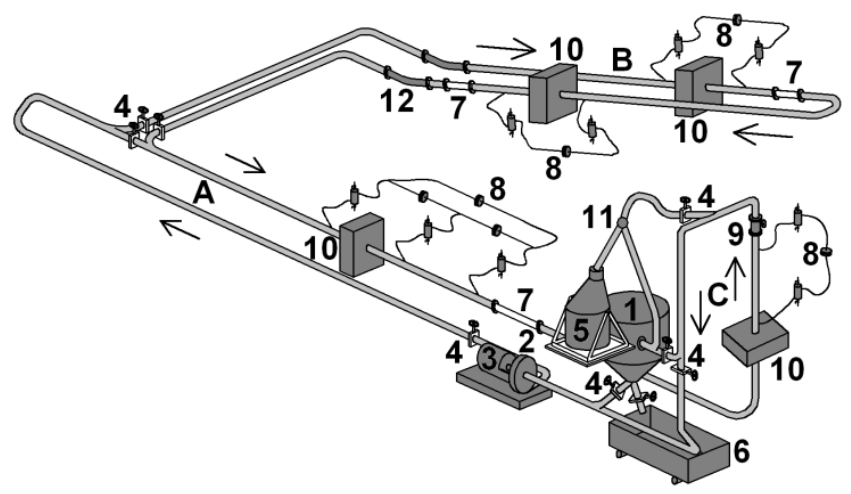

Fig. 1. Experimental test loop at the Institute of Hydrodynamics AS CR, v. v. i., Prague.

A - horizontal section, $\mathrm{B}$ - inclinable section, $\mathrm{C}$ - short vertical section; 1 - mixing tank, 2 - centrifugal slurry pump, 3 - electric motor, 4 - slide valves, 5 - pycnometer, 6 - slurry output tank, 7 - transparent viewing pipe section, 8 - differential pressure transducer, 9 - electromagnetic flow meter, 10 - radiometric device, 11 - flow divider, 12 - flexible hose.

To measure vertical profiles of chord-averaged volumetric concentration and local concentration, $c_{v, L}$, map the loop is equipped with radiometric density meters, which consist of a gamma-ray source (Caesium ${ }^{137} \mathrm{Cs}$, activity $740 \mathrm{MBq}$ ) and of a detector [a scintillating crystal of $\mathrm{NaI}(\mathrm{Tl})]$. Due to the different local absorption properties of the solid particles and liquid the density of mixture or concentration of the solid phase can be determined. A multi-channel digital analyser enables an evaluation of the energy spectrum of the detected signal. A special support, controlled by the computer, serves for positioning both the source and the detector to measure local mixture densities in a pipe cross-section and determining the vertical chordaveraged concentration profiles and the concentration distribution through the pipe. The radiometric device was mounted upstream of the measuring sections in the horizontal part of the loop. A measuring time period of 16 seconds was used to sense the local concentration at each position. It was found to be sufficiently long to suppress fluctuations in gamma ray intensity (Krupicka and Matousek, 2012).

To determine the local concentration distribution through the pipe cross-section, parallel projections of gamma-ray beams were provided at several angles around the pipe axis (i.e. from 0 to $175^{\circ}$ at interval of $15^{\circ}$ ), and the collected data were processed by the computer tomography method. Measurement of the local concentration map is rather time consuming; however it made it possible to evaluate the effect of the slurry velocity, $V_{s}$, and transport concentration, $c_{v}$, on the solids distribution.

\section{MEASURED MATERIAL}

The studied mixtures consist of graded basalt pebbles with a narrow particle size distribution (particle diameter, $d$, ranging from 8 to $16 \mathrm{~mm}, d_{50}=11.0 \mathrm{~mm}$, density $\rho_{p}=2787 \mathrm{~kg} \cdot \mathrm{m}^{-3}$ ). Water was used as the carrier liquid and the transport volumetric concentration of the studied mixtures, $c_{v}$, ranged from 3 to 15\% (Vlasak et al., 2013a).
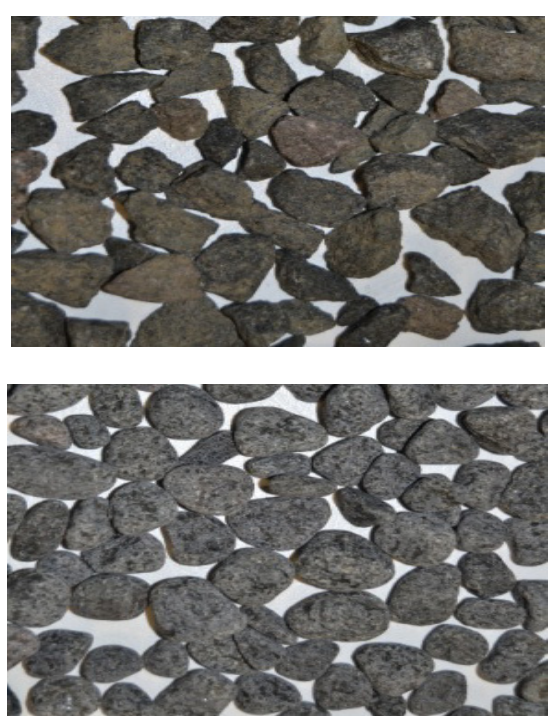

Fig. 2. The graded basalt pebbles; original $\left(d_{50}=11.7 \mathrm{~mm}\right)$ and after degradation $\left(d_{50}=11.0 \mathrm{~mm}\right)$.
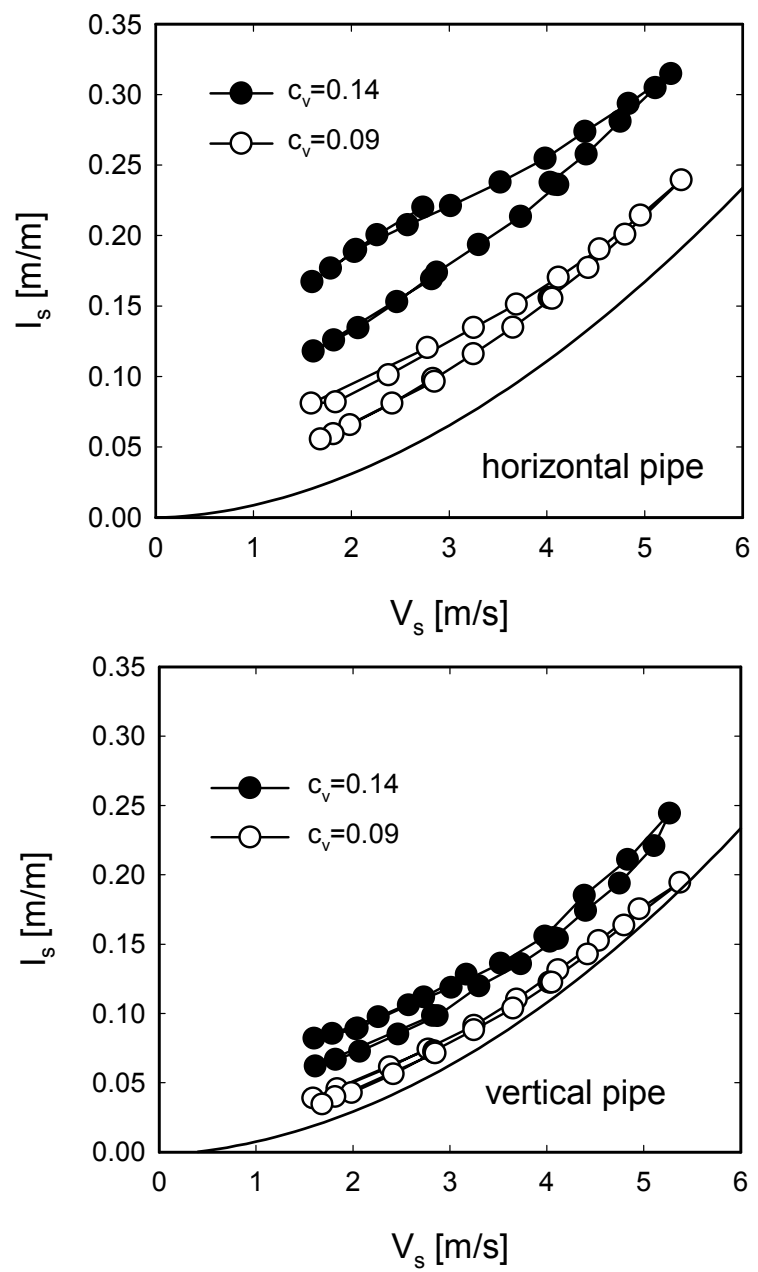

Fig. 3. Effect of particles degradation on pressure drop $i_{s}$ $(D=100 \mathrm{~mm})$.

During the experiments an intensive degradation of solid particles was observed; the originally angular basalt rubble quickly degraded and formed a rounded shape (see Fig. 2). The degradation depends on time, velocity and concentration, for low velocity the degradation process is slow. After short pump- 
ing times at high velocities (over $3 \mathrm{~m} . \mathrm{s}^{-1}$ ) the particle shape and size became practically stabilized. The mean particle diameter changed from the original value $d_{50}=11.7 \mathrm{~mm}$ to $d_{50}=11.0$ $\mathrm{mm}$ (about $94 \%$ of the original value), and the mass portion of particles smaller than $5 \mathrm{~mm}$ did not exceed $10 \%$ even after several hours of pumping.

The effect of particle degradation on dependence of pressure drop, $i_{s}$, on slurry velocity, $V_{s}$, is more significant for flow in horizontal pipe sections than for that in vertical, see Fig. 3. The descending part of $i_{s} / V_{s}$ relationships represents the stabilized (i.e. after degradation of solids) mixture well. It is obvious that the effect of degradation appears mainly for mixture velocities exceeding $3 \mathrm{~m} . \mathrm{s}^{-1}$ and slightly increases with the increasing mean mixture concentration. It is higher for the horizontal pipe section than for the vertical one. To avoid the effect of degradation on mixture flow behaviour during pressure drop and concentration distribution measurements the degraded solid material was used.

\section{MIXTURE FLOW BEHAVIOUR AND PRESSURE DROP}

The effect of the mean velocity, $V_{s}$, and solids transport concentration, $c_{v}$, on the mixture's pressure drop, $i_{s}$, of basalt pebble-water mixtures in horizontal and vertical pipes is illustrated in Fig. 4.

\section{Horizontal conveying}

In the horizontal pipe section the measured mixtures were significantly stratified. From visualization observation it follows that for low mixture velocities (from about $0.80 \mathrm{~m} . \mathrm{s}^{-1}$ ) individual particles slid and rolled along the pipe invert, with increasing velocity bottom formations similar to ripples and dunes originated along the pipe invert. For velocity interval between 1.5 and $2.5 \mathrm{~m} . \mathrm{s}^{-1}$ dunes disaggregated and disconnected sliding bed layer combined with particle saltation over the bed formation was observed. With increasing flow velocity thickness of the sliding bed layer decreases and for moderate and higher flow velocities, particles saltation becomes dominant mode of particle movement. However, most of the particles remained in contact with the pipe wall. Bottom formation contributed to the hydraulic roughness of the respective portion of the conduit, what substantially affected the mixture flow and energy dissipation. The pressure drops are produced mainly due to the mechanical friction between the transported particles and the pipe wall. The relatively high value of slip velocity between conveyed particles and carrier liquid along with mutual particle-particle and particle-pipe interactions and collisions resulted in a significant increase of the total pressure drop (Vlasak and Chara, 2011; Vlasak et al., 2011a).

The particle velocities increased with increasing vertical distance $h$ from the pipe invert (Vlasak et al. 2012, 2014). The velocities of the saltating particles were significantly higher than those of the particles moving in contact with the pipe wall (Lukerchenko et al., 2006).

A practically parallel course of the pressure drop-velocity curve $i_{s} / V_{s}$ was found for water and mixtures of all measured concentrations in the horizontal pipe sections (see Fig. 4). This confirmed the assumption that for fully stratified mixtures the main proportion of frictional energy losses was evoked by Coulomb friction between the solid particles and the pipe wall. Comparison with the results of Wilson and Addie's (1997) horizontal flow model showed that the model overestimated the experimental data and the difference increased with increasing concentration and decreasing mixture velocity.
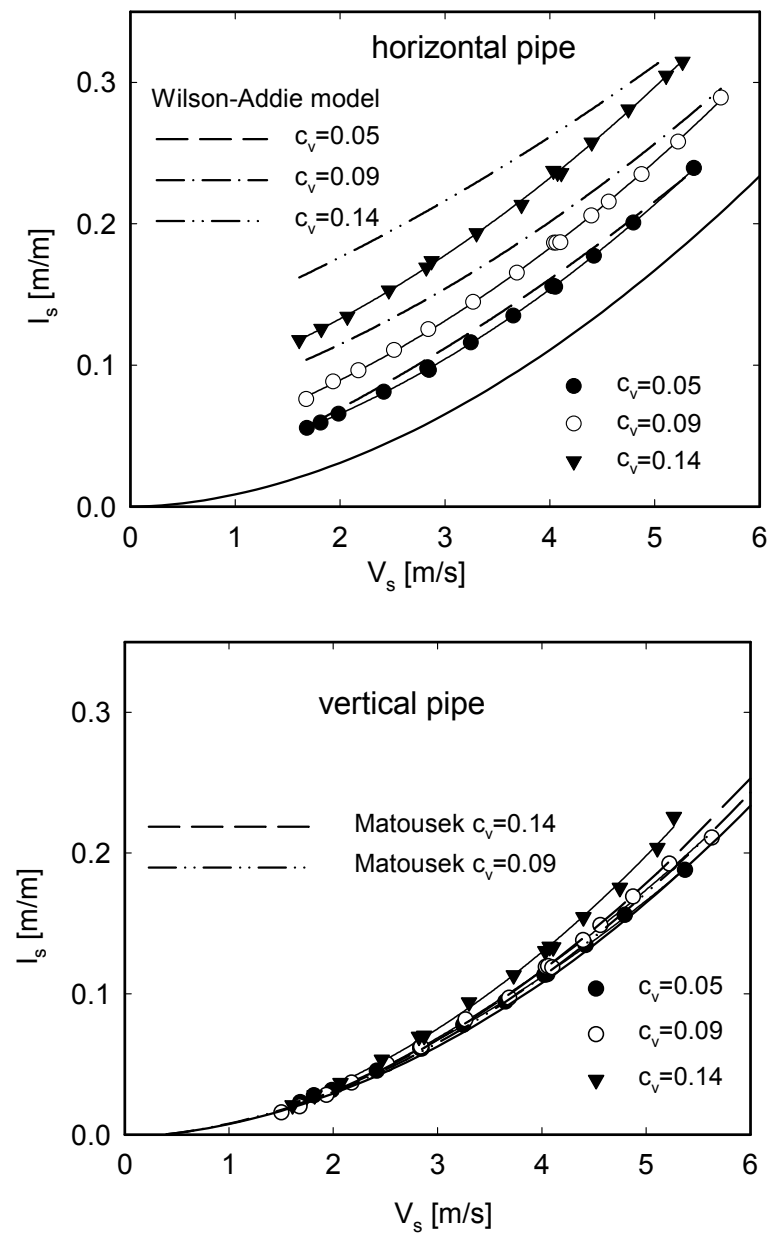

Fig. 4. Pressure drop, $i_{s}$, effect of mean transport concentration, $c_{v}$, and mean mixture velocity, $V_{s}$, in horizontal and vertical pipe sections (basalt pebble-water mixture, $D=100 \mathrm{~mm}$ ). Comparison with results of Wilson and Addie (1997) and Matousek (2009b).

\section{Vertical conveying}

In contrast to horizontal conveyance the particles in the vertical pipe section tend to migrate away from the wall region and concentrate in the core portion of the pipe. Thus the near-wall zone in which most of the shearing occurs can be considered as behaving like a carrier liquid alone (Newitt et al., 1961). When the particles moved mostly in the core portion of the pipe, pressure drops were produced mainly by pipe wall-liquid friction, and the share of inner friction and drag between particles and liquid became less important. The experimental results were compared with the vertical flow model of Matousek (2009b). The vertical model underestimated the measured data, and the difference increased with increasing flow velocity.

As follow from the pressure drop/velocity relationship (see Fig. 4), with increasing concentration and flow velocity, the portion of inner friction increased, some particles migrated to the pipe wall due to the mutual collisions, and consequently the effect of particle-wall friction increased as well as the drag due to particle-liquid slip.

Within the above discussed constraints, the pipe flow should be under conditions where the effect of particle-liquid slip velocity appears to be not very important, that is, when the mixture's mean velocity is at least about four times higher than the hindered particle slip velocity (Wilson et al., 2006). 

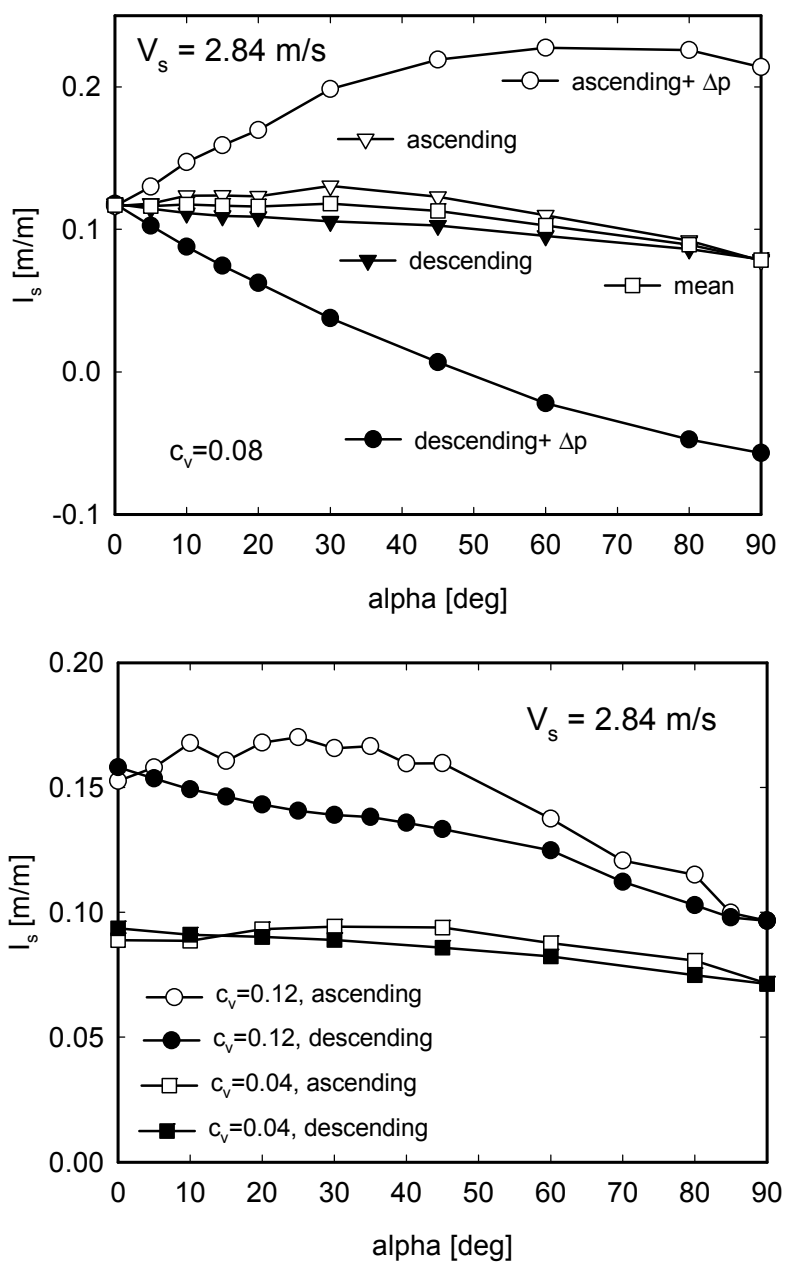

Fig. 5. Effect of pipe inclination alpha on frictional and total pressure drops, $i_{s}$.

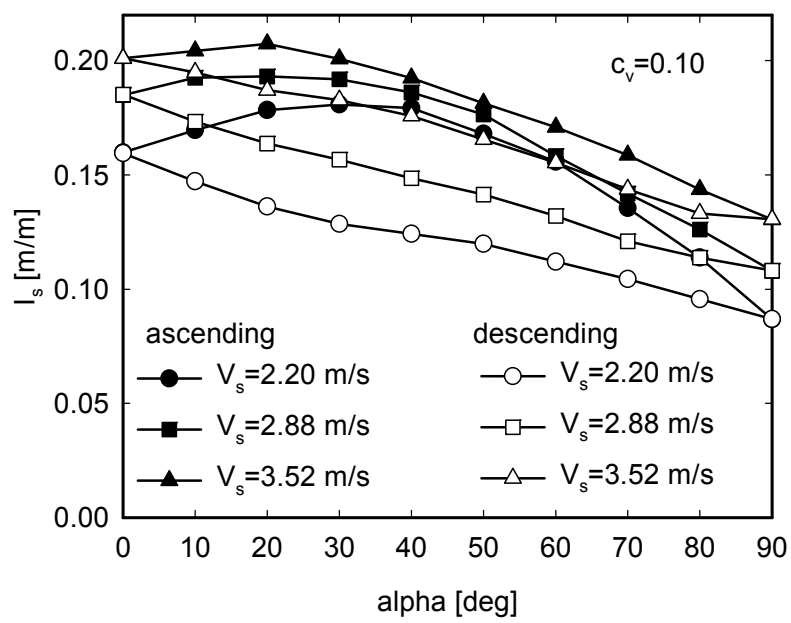

Fig. 6. Effect of mixture velocity, $V_{s}$, and pipe inclination alpha on frictional pressure drop, $i_{s}$, in descending and ascending pipe sections, pipe diameter $D=100 \mathrm{~mm}$.

The experimental result did not confirm the assumptions of some authors (e.g. Newitt et al., 1961) about the almost negligible effect of the large particles on the frictional pressure drop in a vertical pipe. The present results show that the pressure drops of coarse-grained mixtures in vertical pipes increase with the increase solids concentration similarly to the results of Chung et al. (1998).
The frictional pressure drops in the horizontal pipe section were found to be significantly higher than those in the vertical pipe due to the fact, that for fully stratified coarse-grained slurries the contact load produced significant energy losses. The hydrostatic effect $\Delta p=\left(\rho_{s}-\rho_{\mathrm{o}}\right) \cdot g$. $\Delta h$, where $\rho_{s}$ and $\rho_{\mathrm{o}}$ are the densities of the mixture and carrier liquid, respectively, and $\Delta h$ is the height of the mixture column, is not included in Figs. 4-6 (except Fig. 5, $c_{v}=0.08$ ).

The effect of the pipe inclination on the experimental pipe loop was also studied. The pressure drops in an inclined pipe can be described by the well-known Worster and Denny (1955) formula, and can be divided into two parts: non-recoverable frictional pressure drops (energy loss due to the friction between the mixture and pipe), and the hydrostatic pressure difference, which in principle leads to a gain in potential energy.

\section{Inclined pipe sections conveying}

The effect of the pipe inclination on pressure drops was investigated for three values of concentration and three mixture flow velocities $\left(V_{s}=2.20,2.88\right.$, and $\left.3.52 \mathrm{~m} . \mathrm{s}^{-1}\right)$. It was found that for heterogeneous and fully stratified coarse-grained slurries the effect of pipe inclination on frictional pressure drops in ascending pipe section increases with increasing inclination angle up to about $30^{\circ}$, and then gradually decreases. The main increase in pressure drop is, similarly to the case of vertical pipe flow, due to the hydrostatic pressure difference.

Fig. 5 illustrates the effect of pipe inclination on total pressure drops and frictional pressure drops for ascending and descending pipe sections for three values of mixture volumetric concentration, $c_{v}=0.041,0.076$, and 0.123 . The frictional pressure drops are not significantly influenced by the pipe inclination for low concentration values (for $c_{v}=0.076$ the frictional pressure drops are only about $8 \%$ higher; for $c_{v}=0.123$, about $13 \%$ higher, Vlasak et al. (2013b)). Fig. 6 illustrates the effect of pipe inclination on frictional pressure drops for different mixture velocities and concentration $c_{v}$ of about $10 \%$ for a slightly different solid material (density $\rho_{p}=2895 \mathrm{~kg} \cdot \mathrm{m}^{-3}$; particle diameter, $d$, ranging from 8 to $20 \mathrm{~mm}$ ). The effect of inclination on frictional pressure drops could be practically neglected when the mixture's volumetric concentration $c_{v}$ was less than $8 \%$ (see Fig. 5), especially for higher flow velocities.

\section{CONCENTRATION PROFILES AND DISTRIBUTION}

An important parameter for understanding a physical mechanism of the heterogeneous mixture flow is the concentration distribution in the vertical cross-section of the pipe, which has a great effect on the mixture's flow behaviour and pressure drop, too. The concentration distribution in the vertical profile of a horizontal pipe was measured and analysed with the use of a radiometric device. Fig. 7 presents the effect of the mean transport mixture concentration, $c_{v}$, on the chord-averaged local volumetric concentration, $c_{v, L}$, distribution in the horizontal layers of the pipe cross-section for three constant mixture velocities, $V_{s}=1.8,2.8$, and $4.1 \mathrm{~m} . \mathrm{s}^{-1}$.

The concentration profile for the low velocity, $V_{s}=1.8 \mathrm{~m} . \mathrm{s}^{-1}$, can be divided into two parts. The local concentration tends to approach zero in the upper portion of the pipe; the zero concentration regions (i.e. practically only the carrier liquid) increased with decreasing mean mixture concentration and occupied from 30 to $50 \%$ of the profile. A nearly linear concentration distribution can be recognized in the lower portion of the pipe; in the bed layer the concentration increased with increasing mean 

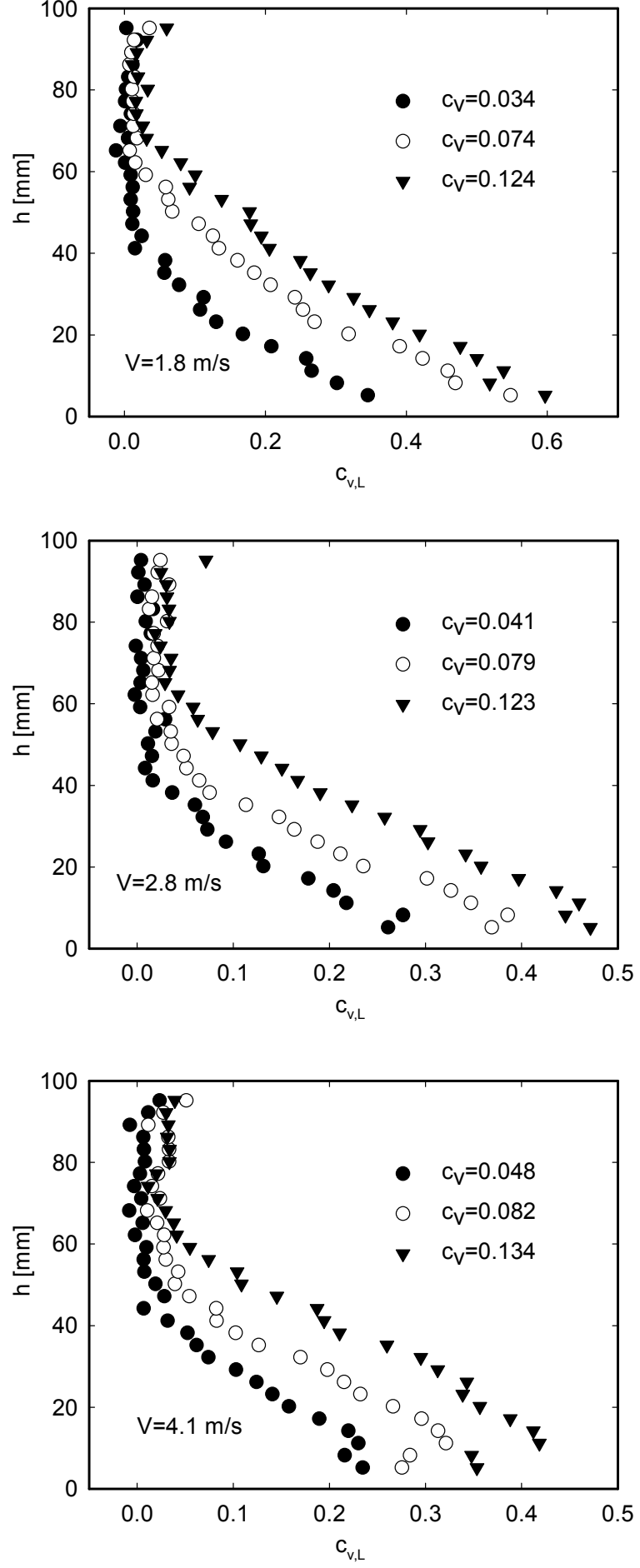

Fig. 7. Vertical profiles of chord-averaged local volumetric concentration, $c_{v, L}$, in a horizontal pipe; effect of the mean transport concentration, $c_{v}$, for constant flow velocity.

concentration from about 40 to $60 \%$, which is close to the loose-packed value.

For the moderate mixture velocity, $V_{s}=2.8 \mathrm{~m} \cdot \mathrm{s}^{-1}$, a similar shape of concentration profiles was observed; however for the lower mean concentration values a layer with a local maximum concentration could be observed at height $h$ from 10 to $12 \mathrm{~mm}$ from the pipe invert. For these concentrations and velocity values, the occurrence of intensive particle saltation was observed. With an increase in the mixture velocity to $V_{s}=4.1 \mathrm{~m} \cdot \mathrm{s}^{-1}$, this
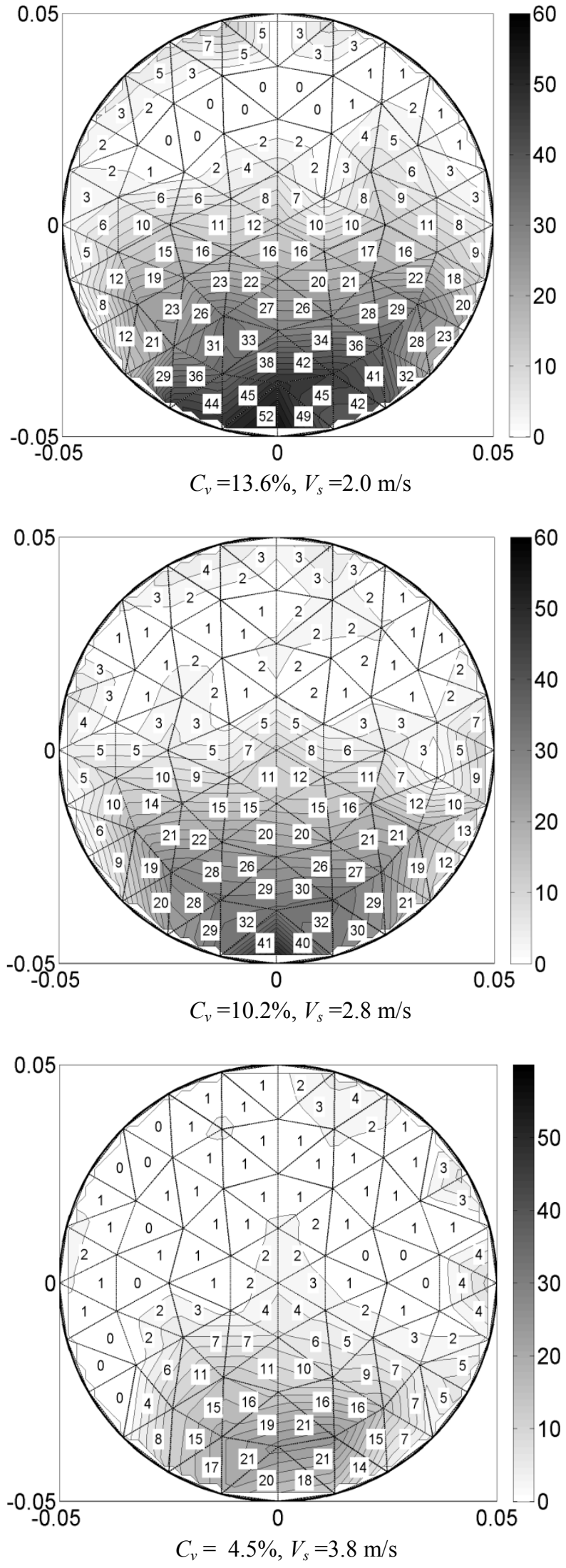

Fig. 8. Local volumetric concentration, $c_{v, L}$, distribution in vertical cross-section of a horizontal pipe; effect of the mean mixture velocity, $V_{s}$, and mean in situ volumetric concentration, $C_{v}$ (determined from integration of the local concentration maps). 
trend increases and the maximum local concentration in the bed layer decreases to $c_{v, L}=0.30$ or $c_{v, L}=0.40$, depending on the mean concentration value. The observed concentration profiles are in good agreement with the profiles measured by Pugh and Wilson (1999), Matousek (2009a) or Sobota et al. (2000, 2009) for heterogeneous mixtures of different solid materials with smaller particle diameters.

From the observed local concentration maps (see Fig. 8), it is evident that conveyed particles tend to occupy the bottom part of the pipe, and their distribution is symmetrical to the vertical plane of symmetry. With increasing mixture velocity and concentration values, even the very coarse-grained particles measured commonly moved in the area above the pipe invert up to one half of the pipe diameter. The observed particle concentration near the pipe's lateral walls was slightly less than that in the central part of the pipe cross-section.

The observed local concentration maps are in good agreement with the concentration maps measured for mixtures of different solid materials with smaller particles (Przewlocki et al., 1979). Some errors were detected in regions close to the pipe wall, and especially near the pipe top, where due to the strong effect of the pipe material on gamma-ray absorption, a higher range of errors was detected (increasing concentration in the area near the pipe top).

\section{CONCLUSIONS}

The study of coarse particle-water mixtures' turbulent flow in horizontal, vertical, and inclined smooth pipes of inner diameter $D=100 \mathrm{~mm}$ revealed that the coarse-grained particle-water mixtures in the horizontal and inclined pipes were significantly stratified and movable or even stationary bed layers were formed. The particles moved principally in a layer close to the pipe invert; for moderate and higher flow velocities particle saltation became the dominant mode of sediment transport and particles were also observed in the central and upper portions of the pipe.

Frictional pressure drops in the vertical pipe were found to be less than in the horizontal pipe due to the fact that the contact load produced significant energy losses in the horizontal pipe. However, the assumption about the almost negligible influence of the large particles on the frictional pressure drops in vertical pipes was not confirmed.

Frictional pressure drops in the ascending pipe section increased (compared to the horizontal pipe section) with increasing inclination angle up to about $30^{\circ}$, and then gradually decreased. The main increase in pressure drops was, similarly to the case of vertical pipe flow, due to the hydrostatic pressure difference.

Measurement of the concentration distribution in the horizontal pipe confirmed that for coarse-grained mixtures the local concentration tends to approach zero in the upper portion of the pipe (from 35 to $65 \%$ of the pipe cross-section), while a nearly linear concentration distribution can be recognized in the lower portion of the pipe. The concentration in the bed layer increased with increasing mean concentration and decreasing mixture velocity from about $40 \%$ up to the values close to the loosepacked value, which demonstrated the formation of a movable or stationary bed layer.

Acknowledgements. Supports under the project P105/10/1574 of the Grant Agency of the Czech Republic, and RVO: 67985874 of the Academy of Sciences of the Czech Republic are gratefully acknowledged.

\section{REFERENCES}

Chung, J.S., Yarim, G., Savasci, H., 1998. Shape effect of solids on pressure drop in a 2-phase vertically upward transport: Silica sands and spherical beads. In: Proc. the Eight (1998) Int. Offshore and Polar Engineering Conf., Montreal, 1998, pp. 58-65.

Durand, R., 1953. Concentration measuring instrument for hydraulic transportation installation. Houille Blanche, 8, 2, 296-297.

Krupicka, J., Matousek, V., 2011. First experimental experience with new laboratory slurry loop. In: Proc. 14th Int. Freight Pipeline Society Symp., Madrid, 28 June-1 July 2011, pp. 147-154.

Krupicka, J., Matousek, V., 2012. Gamma-ray-based method for density sensing in pipes - evaluation of measurement and data processing. In: Proc. 2nd IAHR Europe Congr., Munich (Germany), 27-30 June 2012.

Lukerchenko, N., Chara, Z., Vlasak, P., 2006. 2D numerical model of particle-bed collision in fluid-particle flows over bed. J. Hydraulic Research, 44, 1, 70-78.

Matousek, V., 2009a. Concentration profiles and solids transport above stationary deposit in enclosed conduit. J. Hydraul. Eng. ASCE, 135, 12, 1101-1106.

Matousek, V., 2009b. Pipe wall friction in vertical sand-slurry flows. Particulate Science and Technology, 27, 5, 456-468.

Newitt, D.M., Richardson, J.F., Abbott, M., Turtle, R.B., 1955. Hydraulic conveying of solids in horizontal pipes. Transactions Institute Chemical Engineers, 33, 2, 93-113.

Newitt, D.M., Richardson, J.F., Gliddon, B.J., 1961. Hydraulic conveying of solids in vertical pipes. Transactions Institute of Chemical Engineers, 39, 93-100.

Przewlocki, K., Michalik, A., Wolski, K., Korbel, K., 1979. A radiometric device for the determination of solids concentration distribution in a pipeline. In: Burns, A.P. (Ed.): Proc. of 6th International Conference on the Hydraulic Transport of Solids in Pipes HYDROTRANSPORT 6, 1979, Canterbury (UK), BHRA Fluid Engineering Centre, Cranfield (U.K.), Pap. B3, pp. 219-227.

Pugh, F.J., Wilson, K.C., 1999. Role of the interface in stratified slurry flow. Powder Technology, 104, 221-226.

Shook, C.A., Bartosik, A.S., 1994. Particle-wall stresses in vertical slurry flows. Powder Technology, 81, 117-124.

Shook, C.A., Roco, M.C., 1991. Slurry Flow: Principles and Practice. Butterworth/Heinemann, Boston.

Shook, C.A., Geller, L., Gillies, R.G., Husband, W.H.W., Small, M., 1986. Experiments with coarse particles in a 250 mm pipeline. In: Burns, A.P. (Ed.): Proc. of 10th Int. Conf. on the Hydraulic Transport of Solids in Pipes HYDROTRANSPORT 10, 1986, Innsbruck (Austria), BHRA Fluid Engineering Centre, Cranfield, UK, pp. 219227.

Sobota, J., Plewa, F., 2000. Global and local characteristics of ash mixture flows. EJPAU 3(2), \#01. Available online: http://www.ejpau.media.pl/volume3/issue2/environment/art01.html

Sobota, J., Vlasak, P., Strozik, G., Plewa, F., 2009. Vertical distribution of concentration in horizontal pipeline - density and particle size influence. In: Proc. Eighth (8) ISOPE Ocean Mining (\& Gas Hydrates) Symposium, Chennai (India), 20-24 September 2009, pp. 220-224.

Vlasak, P., Chara, Z., 2007. Effect of particle size and concentration on flow behavior of complex slurries. In: Proc. of the 7th ISOPE Ocean Mining Symp., Lisbon, pp. 188-196. 
Vlasak, P., Chara, Z., 2011. Effect of particle size distribution and concentration on flow behavior of dense slurries. Particulate Science and Technology, 29, 1, 53-65.

Vlasak, P., Kysela, B., Chara, Z., 2011a. Flow behaviour and structure of coarse-grained slurry in horizontal pipe. In: Sobota, J. (Ed.): Proc. 15th Int. Conf. on Transport \& Sedimentation of Solid Particles, Wroclaw (Poland), 6-9 September 2011, 287-298.

Vlasak, P., Chara, Z., Kysela, B., Sobota, J., 2011b. Flow behavior of coarse-grained slurries in pipes. In: Proc. the Nineth (2011) ISOPE (Deep) Ocean Mining (\& Gas Hydrates) Symposium, 19-25 June 2011, Maui (Hawaii, USA), pp. 158-164.

Vlasak, P., Kysela, B., Chara, Z., 2012. Flow Structure of coarse-grained slurry in horizontal pipe. J. Hydrol. Hydromech., 60, 2, 115-124.

Vlasak, P., Chara, Z., Konfrst, J., Kysela, B., $2013 \mathrm{a}$. Experimental investigation of coarse-grained particles in pipes. In: 16th Int. Conf. on Transport \& Sedimentation of Solid Particles, Rostock (Germany), 18-20 September 2013, pp. 265-273.

Vlasak, P., Chara, Z., Konfrst, J., Sobota, J., Kysela, B., 2013 b. Conveying of coarse-grained particles in pipes. In: Proc. Tenth (2013) ISOPE Ocean Mining \& Gas Hydrates Symposium, Szcezecin (Poland), 22-26 September 2013, pp. 215-220.
Vlasak, P., Kysela, B., Chara, Z., 2014. Fully stratified particleladen flow in horizontal circular pipe. Particulate Science and Technology, 32, 2, 179-185.

Wilson, K.C., Addie, G.R., 1997. Coarse-particle pipeline transport: effect of particle degradation on friction. Powder Technology, 94, 235-238.

Wilson, K.C., Addie, G.R., Sellgren, A., Clift, R., 2006. Slurry Transport Using Centrifugal Pumps. 3rd edition. Springer, N. York.

Wilson, K.C., Brown, N.P., Streat, M., 1979. Hydraulic hoisting at high concentration: A new study of friction mechanisms. In: Proc. 6th Int. Conf. on Hydraulic Transport of Solids in Pipes (HYDROTRANSPORT 6). Cranfield, Bedford, UK, BHRA Fluid Engineering, pp. 269-282.

Worster, R.C., Denny, D.F., 1955. The hydraulic transport of solid material in pipes. Proc. Inst. Mech. Engrs., 169/32, 563-576.

Received 7 January 2014 Accepted 24 February 2014 